\title{
Tonometer disinfection and viruses
}

\author{
J. NAGINGTON, ${ }^{1}$ G. M. SUTEHALL, ${ }^{1}$ AND P. WHIPP ${ }^{2}$ \\ From the 'Public health Laboratory Service, Level 6, Addenbrooke's Hospital, Cambridge CB3 2QW, and \\ ${ }^{2}$ Addenbrooke's Hospital, Hill's Road, Cambridge CB2 $2 Q Q$
}

SUMMARY Tonometer disinfectants in current use are frequently inactive against viruses and enable transfer of infection between patients. We selected sodium hypochlorite as a readily available alternative which is active against viruses and bacteria. At 500 p.p.m. it destroys herpes simplex, adenovirus 8 , and enterovirus 70 within 10 minutes. A simple technique is described which is clinically acceptable and has been in daily use for one year.

In December 1981 several laboratory-confirmed adenovirus 8 infections in the Cambridge area led us to consider the possibility of transmission by tonometers should such patients be referred to the Department of Ophthalmology. It was discovered that the tonometer disinfection system in use consisted of immersion in phenyl mercuric borate 1:32000, a method which appears still to be popular but without any evidence to suggest that it is effective against viruses.

In 1968 one of us (J.N.) had investigated an outbreak of herpes simplex infections in another hospital transmitted by an applanation prism and found that phenyl mercuric borate at this concentration had no measurable effect on the infectivity of herpes simplex virus, even after immersion for 1 hour.

An outbreak of adenovirus 8 infection occurred in Bristol in 1971 which involved 40 people, ${ }^{1}$ and 15 patients were considered to have been infected by Goldmann applanation tonometry. ${ }^{2}$ At the time the prisms were either wiped dry or immersed in phenyl mercuric borate. This was considered unsatisfactory, and laboratory tests showed that immersion in phenyl mercuric borate for 15 minutes had no effect on adenovirus 8 . Immersion in 5\% chloramine-T was highly satisfactory and was advised. ${ }^{2}$

In 1979 an outbreak of adenovirus 8 infection occurred in Salisbury, where 14 patients developed symptoms after attending the Eye Department for tonometry (Public Health Laboratory Service, unpublished). The instrument was cleaned between use only with a cetrimide and chlorhexidine compound, and this was considered to be inadequate. The outbreak was brought to an end by measures

Correspondence to Dr J. Nagington. which included tonometer disinfection in $0.6 \%$ chloramine- $T$ for 30 minutes.

There is, then, abundant evidence that tonometry is an infection hazard where viruses are concerned and that the use of phenyl mercuric borate and similar solutions is to be deplored.

We have found in discussion with opthalmological colleagues that the use of these solutions is still a common practice, and recourse to virucidal disinfection is all too often carried out only after an outbreak has been identified and tends to be discontinued when it is over. Chloramine- $T$ is an effective disinfectant, but it is not liked for routine use. Since we consider prevention better than cure, we have investigated the feasibility of using a more acceptable hypochlorite solution routinely in a busy department. This has now been carried out for one year.

\section{Materials and methods}

Three viruses were selected for their relevance in ophthalmology-adenovirus 8 and herpes simplex type 1 , both isolated from recent eye infections in outpatients attending the Eye Clinic, and a strain of enterovirus 70 which was kindly supplied by Dr Mary Roebuck, Central Public Health Laboratory, Colindale.

The viruses were grown to give a high infective yield in human amnion cells (adeno. 8 and HSV 1) and MRC-5 cells (entero. 70) in tissue culture tubes.

At the optimum time for maximum cell-associated virus production the medium was removed and replaced with disinfectant solution for a measured time. The cells were then physically scraped off the glass and deposited by centrifugation to enable 


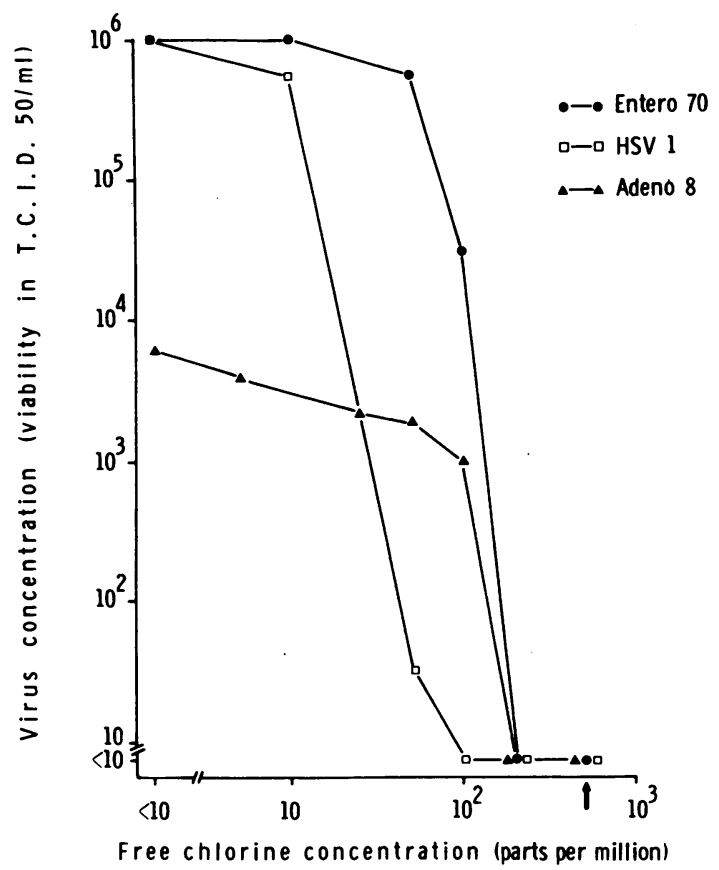

Fig. 1 Antiviral action of hypochlorite. Exposure for 10 minutes. Arrow indicates hypochlorite concentration selected for use in clinic-namelv. 500 p.p.m.

removal of the disinfectant. The cells were resuspended in maintenance medium and the residual virus infectivity measured by titration in fresh tissue culture replicates in microtitre trays. Because adenovirus 8 is more cell-associated than the others it was released by freeze-thawing 3 times before the titration step.

Disinfectants used were sodium hypochlorite (Milton) freshly prepared to contain 500 p.p.m. (parts per million) available chlorine, phenyl mercuric borate 1 in 32000 (formerly supplied under the trade name Merfen), and isopropyl alcohol (isopropanol), which is sometimes used in impregnated tissues.

The concentration of hypochlorite selected was based on the ready availability of this solution, which is only slightly weaker than chloramine- $T$, which at
$0.6 \%$, as at Salisbury, provides 1500 p.p.m. available chlorine. The weaker solution would be likely to be almost equally effective and more acceptable to the users.

\section{Results}

\section{SODIUM HYPOCHLORITE}

The highly satisfactory action of 500 p.p.m. available chlorine from sodium hypochlorite was shown by the finding that none of the 3 viruses remained alive after exposure to it for as little as 2 minutes.

With lower hypochlorite concentrations it was possible to plot a virucidal curve for an exposure time of 10 minutes (Fig. 1). It can be seen that in this time 200 p.p.m. is sufficient to inactivate adenovirus 8 and enterovirus 70 , whereas herpes simplex is destroyed by only 100 p.p.m. Thus a concentration of 500 p.p.m. would give ample margin under clinic conditions.

Measurement showed that solutions allowed to stand in plastic containers lost less than $5 \%$ of the available chlorine in 24 hours.

\section{PHENYL MERCURIC BORATE}

No reduction in viability occurred with adenovirus 8 and herpes simplex even after 1 hour. Enterovirus 70 was reduced in titre from $10^{4 \cdot 5} \mathrm{TCD}_{50}$ to $10^{3 \cdot 0} \mathrm{TCD}_{50}$ in 1 hour, which is not encouraging, and may have been partly due to virus loss due to mechanical factors.

\section{ISOPROPYL ALCOHOL}

This was highly effective against HSV but had negligible effect on the other 2 and was therefore not investigated in detail.

\section{Recommendations}

In view of the highly effective action of hypochlorite against these representative pathogenic viruses and the known efficacy of hypochlorites against bacteria there would appear to be every reason to attempt to use this for the routine disinfection of tonometers. To overcome the problems of its corrosive effect on metal equipment, plastic containers were used, and

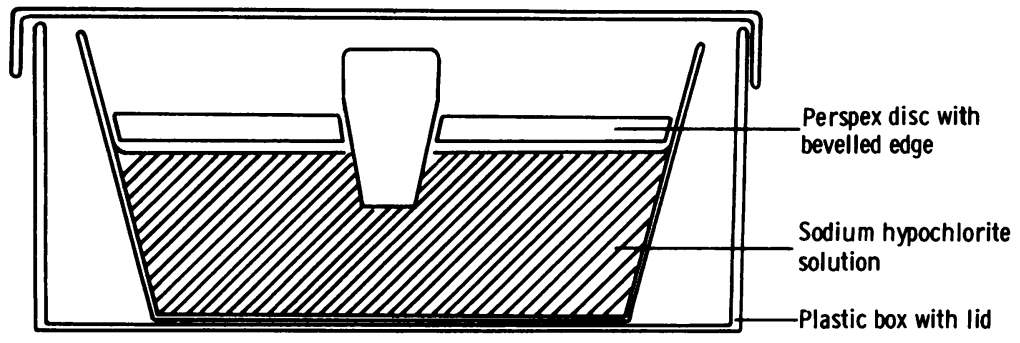

Fig. 2 Adaptation of plastic gallipot to suspend tonometer head in hypochlorite. 
to prevent loss by evaporation these were placed in a closed box. The final method devised is illustrated in Fig. 2.

Sodium hypochlorite solution supplied by the pharmacy at the dilution ready for use is placed in a 60 $\mathrm{ml}$ plastic gallipot and renewed daily. Discs of $3 \mathrm{~mm}$ thick Perspex of approximately $56 \mathrm{~mm}$ diameter with a bevelled edge are made which fit about halfway up this size of pot. The discs have central apertures cut of about 9,18 , and $22 \mathrm{~mm}$; thus most sizes of prism can be held so that the end is immersed in the hypochlorite.

A 10-minute soaking is recommended, after which the prism should be removed, rinsed under the tap, and dried with a fresh paper tissue before being left in a suitable container ready for use again. To prevent evaporation and spillages we find it convenient to place 3 of these pots in one clear plastic lunch box with a lid. A sticker with 'Rinse and dry before use' completes the equipment. The system has now been in daily use for 12 months.

\section{Discussion}

The extent to which patients with eye conditions who are referred to clinics are then infected by tonometry is unknown. It is only when sufficient cases occur to draw attention to themselves that outbreaks are identified and action is taken. Such episodes have been documented throughout the use of tonometry, ${ }^{2}$ and it is likely that a great many more small clusters and single cases pass unnoticed.

It is surprising to find that the traditional phenyl mercuric borate is still in use despite the demonstration of its uselessness. ${ }^{2}$ There are other solutions also in use for their bactericidal action-for example, chlorhexidine gluconate 1 in 5000 is recommended by some manufacturers but it has no virucidal action ${ }^{3}$; quarternary ammonium compounds act orily on enveloped viruses, and we are unaware of any that are comparable to hypochlorite.

In view of the damage which can be caused by herpes simplex and adenovirus 8 infections it is highly desirable to use a disinfectant which will deal with these as well as bacteria. Enterovirus 70 has not so far proved a problem in Britain, but it has caused serious epidemics in tropical countries and in 1981 Central America and the southern USA. The atypical features of this virus include neurovirulence, which produces cranial nerve and limb paralysis. ${ }^{4}$ The mode of spread could be from eye to eye. Should it appear on the scene here it would be reassuring to have a technique in use which would prevent its transfer to other patients. Finally, it may be relevant to endorse the need for hand washing. ${ }^{2}$ Passive transfer of infection on the fingers concerns not only subsequent patients but the medical and nursing staff as well.

We are indebted to Dr M. C. Allwood for advice on hypochlorite and to the staff of the Eye Department. Addenbrooke's Hospital, who helped to set this system working.

\section{References}

1 Barnard DL, Dean Hart JC. Marmion VJ, Clarke SKR. Outbreak in Bristol of conjunctivitis caused by adenovirus type 8 and its epidemiology and control. Br Med J 1973; ii: 165-9.

2 Clarke SKR. Dean Hart JC. Barnard DL. The disinfection of instruments and hands during outbreaks of epidemic keratoconjunctivitis. Trans Ophthalmol Soc UK 1972: 92: 613-8.

3 Russell AD. Hugo WB. Ayliffe GAJ. Principles and practice of disinfection. preservation and sterilisation. Oxford: Blackwell. 1982.

4 Editorial. Neurovirulence of enterovirus 70. Lancet 1981; i: 373-4. 